\title{
Developing a Cognitive Assistant for the Audit Plan Brainstorming Session
}

Qiao Li. Rutgers, the State University of New Jersey. USA qiao.li1218@rutgers.edu

Miklos Vasarhelyi. Rutgers, the State University of New Jersey. USA miklosv@business.rutgers.edu

\begin{abstract}
With technological advances, audit firms have been able to increase the level of decision support embedded within the firms' audit support tools (Dowling et al., 2008). Large audit firms have been investing substantive resources into the utilization of Artificial Intelligence (AI) to take advantage of their past audit experience and industry knowledge (Kokina and Davenport, 2017; Appelbaum, 2017). During the initial stages of an audit, the engagement team will meet to update their understanding of the client through brainstorming sessions. Audit firms are required by SAS No. 99 and SAS No. 109 to use brainstorming sessions to evaluate risk factors and discuss the susceptibility of the entity's financial statements to material misstatement, either as a result of error or fraud (AICPA, 2012). At present, the most commonly used decision support tool for audit plan brainstorming is the checklist (Bellovary and Johnstone, 2007), which has shown limitations (Dowling and Leech, 2007; Seow, 2011; Landis, 2008). To improve audit plan effectiveness, this study proposes an audit domain cognitive assistant system to provide interactive decision support for information retrieval and risk assessment in audit brainstorming session. Cognitive Assistants are speech-enabled technologies that can understand voice commands, recognize conversation's context, and answer questions in a personable manner (Garrido et al., 2010; Myers et al., 2007).
\end{abstract}

Keywords: cognitive assistant, cognitive computing, audit plan brainstorming

\section{INTRODUCTION}

The intrinsic nature of auditing allows for the use of audit software which can provide auditors assistance in a variety of tasks. In today's information world, 
auditors need to use many data sources to understand and evaluate the industry and the business of audit clients. In addition to traditional financial information, auditors should expand to non-financial information from external sources such as news articles and social media. Accounting and auditing are changing fundamentally due to the improvement in data analysis and AI (Kokina and Davenport, 2017; Appelbaum, 2017).

Audit firms have nowadays been investing many resources into AI-related projects (Greenman, 2017). KPMG signed a broad agreement with IBM to apply IBM Watson to a series of audit processes (Lee, 2016). KPMG's cooperation with Watson tries to develop selected cognitive services designed to help KPMG "meet its extensive audit-specific security, confidentiality and compliance requirements" (IBM, 2017). Deloitte is trying to assemble different cognitive capabilities from various vendors and integrate them to support audit processes, such as document review and predictive risk analytics (Raphael, 2017). PwC and EY are increasing their usage of audit platforms and predictive analytics (Kokina and Davenport, 2017).

Cognitive Assistants or Intelligent Personal Assistants (IPA) are speech-enabled technologies that use a natural spoken language and semantic understanding techniques to communicate and interact with human and help human obtain wanted information (Canbek and Mutlu, 2016). These tools allow users to input information such as the user's voice, vision (images) and contextual information, and then provide instant assistance to users through answering questions and performing actions (Hauswald et al., 2015). Examples of commercial IPAs include Apple's Siri, Google Now, Microsoft Cortana, Amazon's Echo/Alexa, IBM's Watson, etc. ${ }^{1}$ (Canbek and Mutlu, 2016; Mehrez, 2013; Ebling, 2016; Bellegarda, 2013; Strayer et al., 2017). Current cognitive assistants have shown their usefulness in people's daily lives, but the technology has been slow to be applied to the work environment. Cognitive assistants are great tools for business situations when users need information retrieval support from a large amount of knowledge sources.

\footnotetext{
1 Other commercial IPAs are BlackBerry's 'BlackBerry Assistant', Braina, HTC's 'Hidi', Maluuba Inc's 'Maluuba', Motorola's Mya (unreleased), Samsung's 'S Voice', Cognitive Code's 'SILVIA', Nuance's 'Vlingo', LG's 'Voice Mate'
} 
This study proposes that cognitive assistant technology can be applied in the accounting and auditing domain. During audit planning and risk assessment, a critical step is usually to hold brainstorming meetings (Bellovary and Johnstone, 2007). During the brainstorming stage, the engagement team members exchange ideas about how and where they think the client's financial statements may be susceptible to material misstatement due to fraud and how management could perpetrate and conceal fraudulent reporting or misappropriate assets (Beasley and Jenkins, 2003). Considering the importance of the brainstorming session and the limitation of existing audit decision support tools for the process (Dowling and Leech, 2007; Seow, 2011; Landis, 2008), in this paper, a cognitive assistant framework is developed for the audit plan brainstorming session with the objective of providing timely information retrieval and decision-making support for audit engagement team members.

This study will contribute to the literature and practice in three main aspects. First, this is the first study discussing how cognitive assistant and cognitive computing technologies can be applied in accounting and auditing domain. Second, this study proposes a general framework for developing an intelligent audit cognitive assistant to support auditors in audit plan. Third, the proposed tool provides a new method of knowledge organization for the audit domain, which potentially develops a knowledge base that stores many senior auditors' knowledge and experience in audit risk identification and assessment.

\section{BACKGROUND ON AUDIT BRAINSTORMING SESSIONS}

Two auditing standards mandate brainstorming sessions, SAS No 99 and SAS No 109 (AICPA, 2002). SAS 99 requires auditors identify specific fraud risks and SAS 109 requires auditors identify additional causes of potential material misstatement in the financial statement during brainstorming (Landis, 2008; Hammersley et al., 2010; Carpenter, 2007; Hoffman and Zimbelman, 2009; Bellovary and Johnstone, 2007; Hunton and Gold, 2010; Lynch et al., 2009). The participating team may include the whole audit team, including audit partner, audit manager, senior and new staff, and the time spent on the session varies from 15 mins to 2 hours, mainly 30 mins to 1 hour (Bellovary and Johnstone, 2007).

Studies show that audit engagement teams tend to generate more high-quality ideas on fraud risks as a group than as individuals (Landis, 2008; Beasley and Jenkins, 2003; Carpenter, 2007; Hoffman and Zimbelman, 2009). Inefficiencies 
and distractions of brainstorming sessions will ultimately affect the audit team's ability to identify fraud risks and hinder key audit decisions, leading to dangerous paths (Beasley and Jenkins, 2003).

Currently, audit firms usually use a checklist as the decision support tool during audit plan brainstorming sessions (Bellovary and Johnstone, 2007), but there are some issues with this decision support tool. A checklist can be considered as a structurally-restrictive decision aid tool as it shows a list of risk areas to guild brainstorming discussions. Seow (2011) shows that the more structurallyrestrictive decision aid imposes more limits on users' decision-making process and induces biases because users are forced to adapt their decision-making to match the guidance in the tool. This type of decision aid reduces users' ability to identify new items that did not appear in the tool when users focus only on the items prompted by the tool and fail to adequately consider other possibilities in a particular situation (Seow, 2011; Asare and Wright, 2004; Dowling and Leech, 2007). A checklist with standard items cannot cover all risks for a specific client; therefore, in the brainstorming sessions, checklists may limit auditors' ideas in identifying new potential risks.

Also, psychology research showed that an auditor who uses checklists tend to believe that a risk factor listed on the list is less severe than auditors who don't use them. The reason is that people are more likely to consider their ideas more critical and relevant than ideas suggested by others (Landis, 2008), such as the risks on checklists. Moreover, when utilizing checklist, engagement team members still need to recall information from memory or look for information from pertinent documents, which take time and require much preparation work from auditors. Therefore, although a checklist is an essential and accessible decision support tool for audit plan, there is a lot of room for the improvement of audit decision support tools.

\section{FEATURES OF COGNITIVE ASSISTANTS AND THEIR ADVANTAGES IN IMPROVING AUDIT PLANNING}

At present, the most important benefits of cognitive assistants include offering information retrieval, supporting users with recommendation systems, adaptive learning capability and service delegation systems (opening linked applications) (Garrido et al., 2010; Myers et al., 2007). The benefits of cognitive assistants make them excellent tools for the audit field, especially the processes where 
auditors need information and decision support based on a massive amount of data sources. Figure 1 shows the main features of a typical cognitive assistant and how these features can benefit audit brainstorming sessions.

\section{Main Features of \\ Cognitive Assistants}

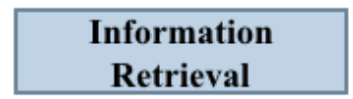

\section{Recommendation Support}

\section{Adaptive Learning}

\section{Service Delegation}

Potential Support in Audit

Plan Brainstorming
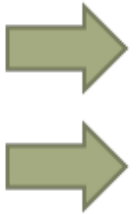

Recommend discussion topics and potential risks

Collect knowledge and experience from senior auditors

Audit applications / program connection

Figure 1. Features of Cognitive Assistants and Benefits to Audit Brainstorming

Firstly, a cognitive assistant can provide information retrieval support to the engagement team at industry and client level. Primary information sources for audit brainstorming such as financial statements, regulation, analytical procedures guidance, etc. can be stored in the knowledge base of a cognitive assistant. Auditors should be able to ask questions to the tool to receive answers.

Secondly, a cognitive assistant can provide recommendations to users for decision making through its recommender system. Since this tool is proposed to provide decision support for audit plan brainstorming, suggestions on risk areas and discussion topics for a specific engagement case should be provided to auditors. For example, when auditors interact with the tool during an audit plan brainstorming, it will generate recommendations to auditors for discussion on potential risks areas (such as Business Risks), and for each risk area, it will then give recommendations on more detailed topics (such as Litigation, Reputation, Acquisitions and Consolidation etc. on Business Risks). Initial recommendations will be needed to set up a recommender system. For the audit cognitive assistant, the initial recommendations can be created based on risk areas mentioned in the auditing standards and knowledge extracted from experimental brainstorming cases. 
Thirdly, there is a learning curve with a cognitive assistant, and it can adapt itself by interacting with users and learning users' preferences over a wide range of functions within the system (Myers et al., 2007). For instance, Google Now can recognize repeated actions that users perform on the device such as repeated calendar appointments and search queries, and therefore can display more relevant information to the user. When more auditors use the tool in brainstorming discussions, experience and domain knowledge in risk assessment from senior auditors will be collected through interactions with the cognitive assistant; then the tool will increase its knowledge base and adapt itself with numerous auditors' "thinking" and become smarter. As the system will collect what has been "searched" from different senior auditors, it is supposed to provide improved recommendations on vital risk areas and discussion topics through its recommender system when more auditors use it.

Fourthly, Cognitive Assistants have service delegation systems (Garrido et al., 2010; Canbek and Mutlu, 2016; Ebling, 2016), which can invoke various apps to complete tasks such as setting a timer, sending messages, getting directions, creating reminders, reminding daily appointments, responding to questions (Canbek and Mutlu, 2016). A cognitive assistant for audit planning could complete tasks such as opening linked third-party applications for auditors when they need them during their risk assessment, such as a calculator, data analytical tools/programs used in the firm, calendar. These functions save auditors time in the brainstorming meetings and allow the engagement team members focus more on more important tasks in the risk assessment conversations.

\section{PROPOSED AUDIT COGNITIVE ASSISTANT FRAMEWORK}

Figure 2 is the proposed architecture of the audit domain cognitive assistant. The proposed audit cognitive assistant framework includes three main parts: user interface, cognitive assistant architecture and knowledge base.

\subsection{User Interface}

The natural language user interface allows system users to interact with the system. The proposed tool is named as Luca, and users should be able to rouse the tool when calling Luca. When a user starts a brainstorming meeting, he/she is supposed to select the industry, client company name, and his position in the engagement team from the home page. 


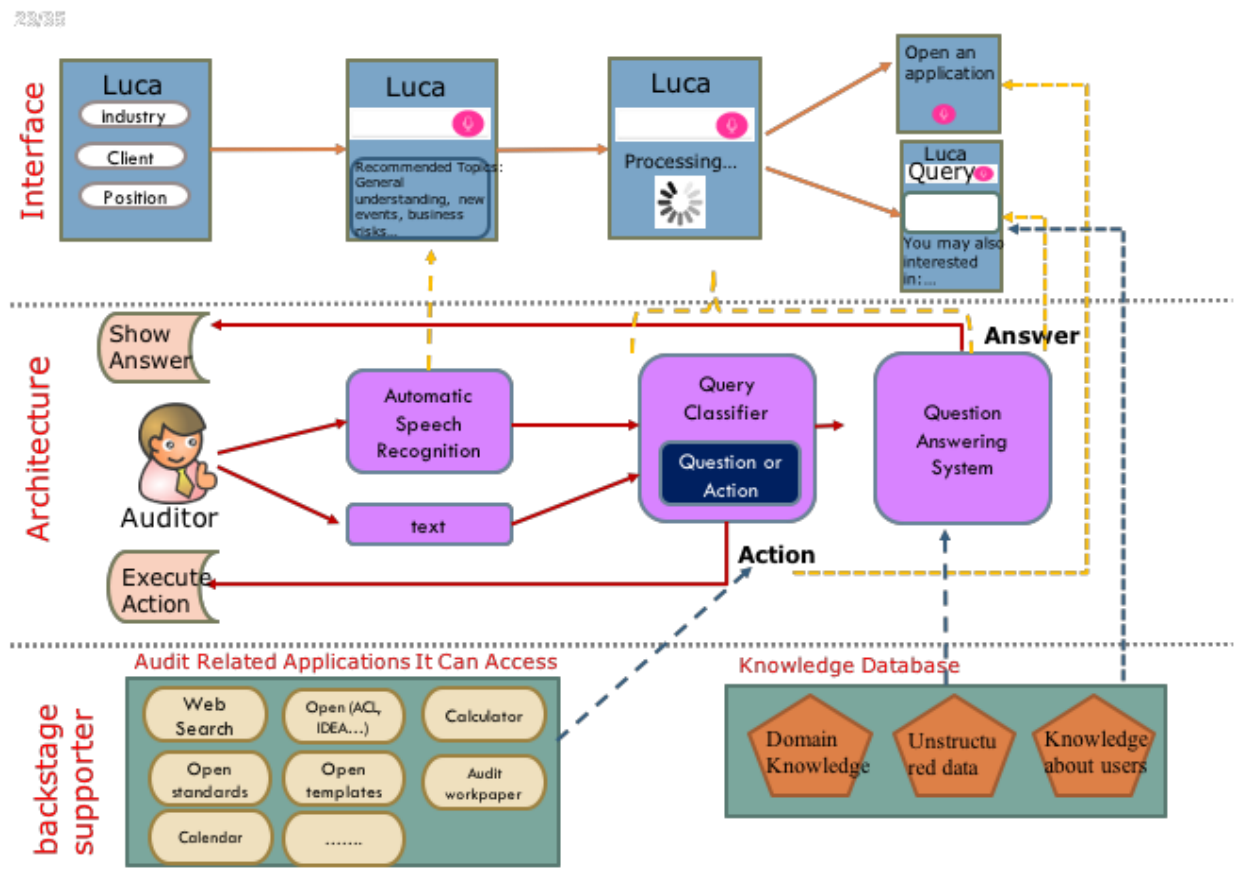

Figure 2. Proposed Framework of the Audit Cognitive Assistant

Industry and company must be selected at the beginning of the usage for two main reasons: access control and recommendation support. First, in an audit engagement case, the engagement team members should only be authorized to access to information sources that relevant to the case, while data about other clients stored in the knowledge base should not be accessible by these auditors. The selection of industry and client name is the control for information access. Second, since data sources in the knowledge base are supposed to be categorized and tagged, the recommender system and question answering system will process faster in preparing answers to selected industry and client. By choosing the position of the user, such as partner, manager, junior auditor, tax expert, IT expert, etc., the cognitive assistant will be able to learn and memorize queries and actions performed by different auditors, then provide relevant and customized recommendations to following users. For example, if the audit manager is new to the team, when interacting with the tool, he will receive recommended discussion topics that raised by other senior auditors when they assess risk for this client or similar clients in this industry in the prior audit. 
Examples of the question - answering interaction can be:

Q: Where are the new stores that xxx opened this year?

A: There are five new stores for $x x x$ in 2016:

Three stores in Mexico: $x x x$

Two stores in Canada: $x x x$

Q: List the new acquisitions and new joint ventures of $\mathrm{xxx}$ this year.

A: There is one acquisition in $x x x$ in 2016: $x x x$

Q: Does xxx have new suppliers?

A: There is one new partner in $x x x: x x x$

Q: Does xxx have new contracts or covenants?

A: There are no new contracts or covenants found in 2016.

\subsection{Recommender System}

Since this audit domain cognitive assistant is proposed to provide decision support for the audit engagement team during audit plan and risk assessment, it is crucial that it can give domain knowledge for decision support. The recommendation system knowledge is built based on two knowledge sources: risk areas required by audit and regulations and audit procedures of audit firms, and knowledge that the cognitive assistant learned from user interactions (through auditors' queries).Therefore, as more auditors interact with the tool, it will react better by providing more targeted recommendations. For example, the recommender system should include pre-programmed important risk areas that an engagement team usually discuss during a brainstorming meeting. Examples of the main risk areas for discussion can be General Understanding of the Firm, New Events, Significant Accounts, Business Risks, Fraud Risks, Going Concern, IT Controls, Related Parties, etc. Based on selected industry and client, maybe only part of these risk areas from the list will be recommended to the engagement team according to the importance level defined by the system.

Then, for each risk area, more detailed discussion topics should be recommended to auditors. For instance, suggested discussion topics under General Understanding of the Firm can be Company Information, Management, Business 
Strategy, Industry Environment, Economic Factors, etc. Since each industry may have industry-specific risk areas and discussion topics to focus, both general topics and industry-specific topics should be designed in the recommender system.

\subsection{Architecture}

The middle layer is the proposed architecture of the cognitive assistant. Auditors can interact with the proposed tool by talking to it or typing in the question that they want to ask. Automatic Speech Recognition (ASR) will process auditors' voice and then translate his/hervoicequestion into its text equivalent through analytical models. The translated text then goes to Query Classifier which decides if the command is an action or a question. If it is a question, then command goes to the Question Answering (QA) system. QA system will extract information from the question, search its database, and choose or generate the best answer and return to the user. For example, when auditors discuss how weather and seasonality issue may affect the sales performance of stores of a client, they may want to ask the cognitive assistant "which stores may be affected by weather?". Then the tool should look for weather-related information from historical records and prepare an answer. The answer could be a list of stores locations that were affected by hurricanes (such as south, southeast, east coast) and those not in prior years, together with related insurance coverages and losses. Also, the answer may also include predicted risky store locations based on recent weather news and predictions. If it is an action, the command is sent back to the system to execute the required application.

This architecture is proposed based on the structure of Sirius. Sirius is an open intelligent personal assistant system built by University of Michigan engineering researchers with both speech and image front-ends. Sirius works similar to Siri, Microsoft Cortana and Google Now, but besides accepting voice commands, it allows users to ask questions about what they are seeing (Hauswald et al., 2015). However, considering the information needs of auditors during audit plan brainstorming, image recognition function in Sirius is not considered in the proposed tool. 


\subsection{Applications}

Applications are the third-party apps that are linked to the proposed audit cognitive assistant for direct execution. During the audit brainstorming meetings, auditors use information from various documents to discuss client and make judgments, therefore service delegation function in the cognitive assistant become an "information and task manager" that help improve the work efficiency of auditors during the process and make them focus more on important tasks such as risk discussions. For example, auditors may be interested to know new information such as economic factors and latest events about a client during the risk assessment, and an app of "web search" allows information that cannot be found in the current knowledge base to be seen through existing online search engines. Only audit plan related applications should be linked to this proposed tool. Capabilities of some proposed relevant apps are listed in the table below (Table 1).

\begin{tabular}{|l|l|}
\hline App & Capability \\
\hline Audit analytical tool & $\begin{array}{l}\text { Support audit data analytics such as statistical and predictive } \\
\text { analysis }\end{array}$ \\
\hline Audit working papers & Provide evidence from prior audit working papers \\
\hline Calculator & $\begin{array}{l}\text { Support financial ratios analysis for Financial Statement; other } \\
\text { data analytical calculations such as Benford's law (Nigrini, 2012; } \\
\text { Dai and Li, 2016) }\end{array}$ \\
\hline Templates & $\begin{array}{l}\text { Guidance or programs designed by the audit firm for required } \\
\text { procedures in risk assessment }\end{array}$ \\
\hline Standards & Regulations related to the audit area or financial account \\
\hline Web search & $\begin{array}{l}\text { Direct search from search engine such as Google; used when } \\
\text { information cannot be found in existing knowledge base }\end{array}$ \\
\hline
\end{tabular}

Table 1. Proposed Apps

\subsection{Knowledge base}

The knowledge database is used to store audit brainstorming related data sources to support the QA system. The knowledge base should include both structured data and unstructured data that could be used by the engagement team during 
audit plan risk assessment. Organized knowledge storage free the audit partner and manager from memorizing tremendous amount of information. It provides efficient information retrieval during brainstorming sessions for questionanswering interactions.

Text resources are unstructured data sources stored in the knowledge base. Phrases, sentences, and paragraphs in all text resources will be tagged based on pre-determined question category and answer type to enable the information in those texts to be extracted by algorithms during user query. Data sources include financial statements, accounting policies, analytical procedures, litigation, claims, recent news information, audits working papers, prior year audit deficiencies and adjustments, etc. For example, the amount of a firm's Accounts Receivable - Net in the Balance Sheet should be tagged based on several keywords: firm's name, fiscal year, annual financial report, balance sheet, and accounts receivable - net. Then when an auditor generates a question such as "what is $\mathrm{xxx}$ (firm's name)'s accounts receivable in the annual financial statement of 2016?", the tool will know that the question category is of this query is "Annual Financial Report", and then look for best answer from the corresponding sub-knowledge base.

Domain knowledge means collected experience and expertise from auditors. Some of these insights are essential facts about client financial situation that could be collected and prepared before a discussion meeting. Some knowledge is judgments or experiences that were extracted from prior audit documents, which provide important insight for current new cases. This domain knowledge can be prepared and stored in the cognitive assistant as questions and answers, and they should be stored as structured data a relational database.

The third type of knowledge is new knowledge gained through user interactions with the tool. Based on user's queries and behaviors, related new knowledge about users is collected for future recommendations in similar situations.

\subsection{Important modules in the proposed system}

When applying cognitive assistant technology into a new field such as audit domain, one strategy is to utilize from public computer domain modules. The audit plan cognitive assistant framework in this paper is proposed based on architecture and modules of current commercial cognitive assistants. The most important components used for speech-driven cognitive assistant include Speech 
Recognition, Spoken Language Understanding, Language Generation, Question Answering System, Dialog Manager (Query Classifier), and Text to Speech (Mehrez et al., 2013; Bellegarda, 2013; Hauswald et al., 2015). Figure 3 shows an example of how a current cognitive assistant is structured (Mehrez et al., 2013). In their architecture, language understanding and language generation are implemented within its question-answering system. Dialog manager module is used to decide if the user's command is an action or a question. The text-to-speech component will transform answers in natural language text to voice responses.

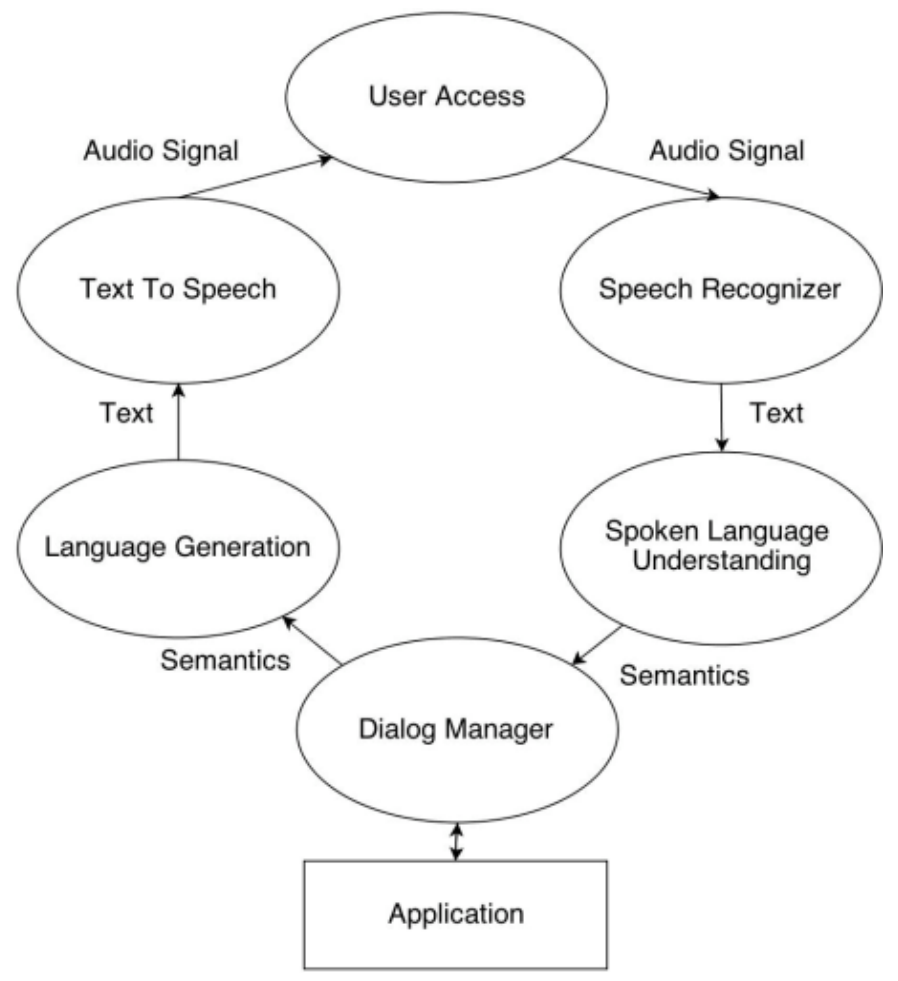

Figure 3. A basic cognitive assistant architecture (Mehrez et al., 2013)

\subsubsection{Speech Recognition}

Intelligent personal assistants such as Apple's Siri and Amazon's Alexa leverage machine learning techniques, including Deep Neural Networks (DNN), convolutional neural networks (Tang and Lin, 2017), long short-term memory units (Chen et al., 2015), gated recurrent units (Ravuri and Stolcke, 2016), and ngrams (Daelemans, 2013; Levy, 2016) to build smart voice recognition system. 
These techniques can be used in building the cognitive assistant system for audit domain as well. Developers can also integrate components from well-established open source projects which include methods and algorithms used in commercial systems. For speech recognition, popular open projects include Carnegie Mellon University's Sphinx (Gaussian Mixture Model based) (Huggins-Daineset al., 2006), Microsoft Research's Kaldi (Poveyet al., 2011) and Germany's RWTH Aachen "RASR" (Deep Neural Network based) (Rybach et al., 2011).

\subsubsection{Language Understanding and Language Generation}

\section{(Natural Language Processing)}

Since the 1950s, Natural Language Processing (NLP) research has been focusing on tasks such as machine translation, information retrieval, text summarization, question answering, information extraction, topic modeling, and opinion mining (Cambria and White, 2014). It uses computational techniques to learn, understand, and produce human language content. Speech recognition and speech synthesis are part of NLP, and it is widely used in real-world applications, creating spoken dialogue systems and speech-to-speech translation engines (Hirschberg and Manning, 2015).

With the help of NLP, voice commands and natural language questions from auditors should be translated into "parsed text" that the computer programs can understand. In the proposed cognitive assistant, NLP should be implemented within its question answering system so that it can understand auditors' questions and generate answers.

\subsubsection{Question Answering (QA) system}

Question answering (QA) techniques provide answers to questions that rely on complex NLP techniques. QA systems have been implemented in healthcare, finance, marketing, and education. Apple's Siri and IBM's Watson are examples of commercial QA systems. QA system is one of the most critical functions of the proposed intelligent system. QA system development has a long history, with three main modern paradigms of question-answer systems: (1) IR-based question answering; (2) knowledge-based question answering; and (3) hybrid approach question answering (Gandomi and Haider, 2015). Apple's Siri is an example of a knowledge-based approach. In hybrid QA systems, like IBM's Watson, while the question is semantically analyzed, candidate answers are generated using the IR 
methods (Gandomi and Haider, 2015). One application of Watson is the medical industry where it analyzes patients' medical information against a considerable amount of data and expertise to offer evidence-based treatment options (Ebling, 2016).

One crucial feature of Watson's Deep QA is its cognitive computing technology. Cognitive computing refers to systems that learn at scale, reason with purpose, and naturally interact with humans. It can learn, reason and improve machine "knowledge" from their interactions with humans (Goffman, 2016). Cognitive technology allows "greater collaboration between humans and systems, providing the ability to communicate in the natural language and analyze massive amounts of data to deliver insights more quickly" (IBM, 2017). There had been a trend of applying this technology into accounting and auditing domain: "Many audit, tax, advisory and other services rely heavily on judgment-driven processes. Adding cognitive technology's massive data analysis and innovative learning capabilities to these activities has the potential to advance traditional views on how talent, time, capital and other resources are deployed by professional services organizations"(IBM, 2017).

To satisfy the needs of question answering in the audit plan risk assessment in brainstorming meetings, the question answering system in the proposed cognitive assistant should involve both knowledge-based QA (cognitive QA) and IR-based QA (domain QA). The proposed QA system architecture (Figure 4) is built based on existing QA models (Mehrez et al., 2013; Ferrucci et al., 2010; Chung et al., 2004).

In the proposed architecture, first of all, the questions are normalized to be accessible for query generation. Normalization includes question analysis, keyword extraction and named entity recognition to generate a proper query for this question. Punctuations are removed, abbreviations are expanded and nouns and verbs are stemmed. Then the generated query will be used to search from the knowledge base. With the extracted type of question, Answer Matching method is used to find possible answers. If the QA system can find pre-paired answers stored in a relational database like traditional domain QA systems (Chung et al., 2004), then the NL answer generating module will generate an answer to the user (path (1) in Figure 4). 


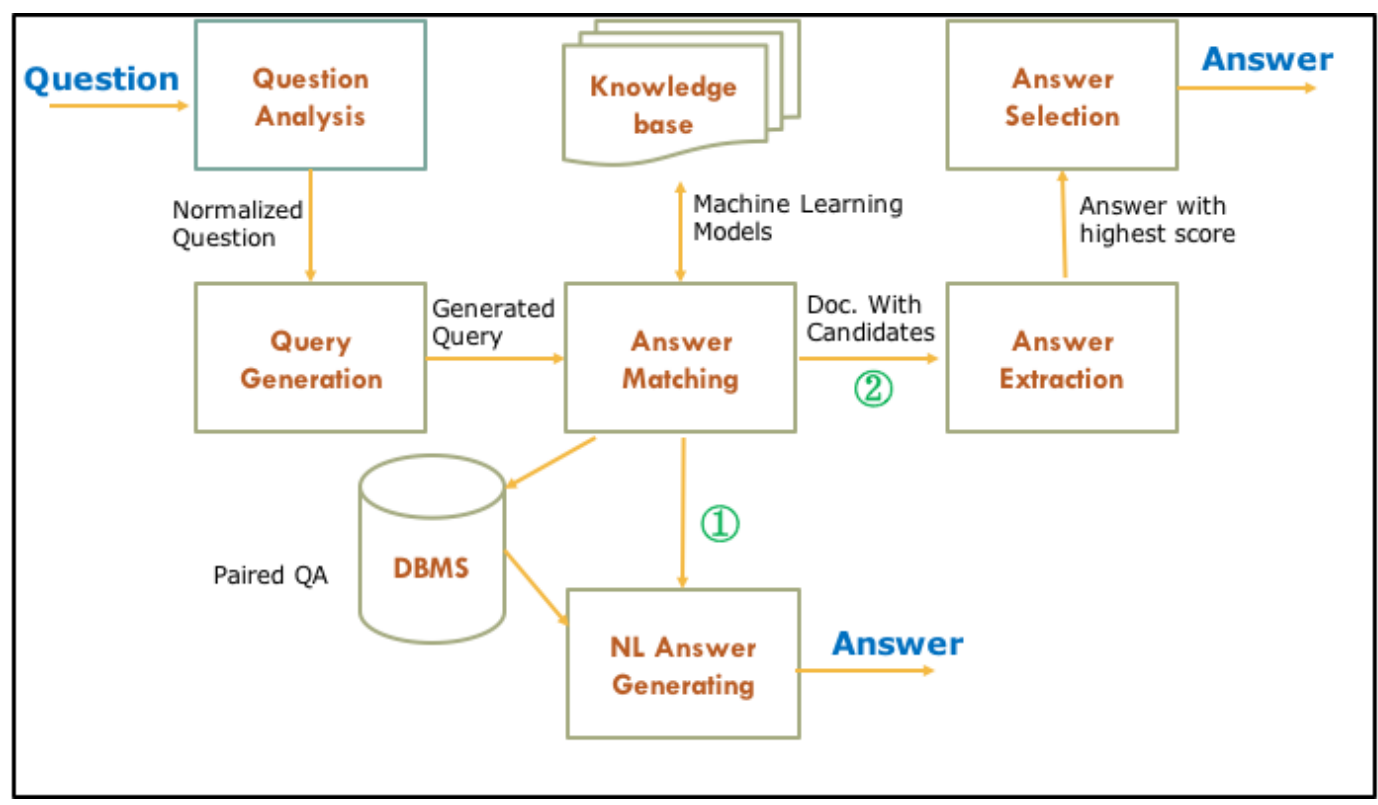

Figure 4. Proposed QA System

If there is no pre-prepared question type or answers for the question, cognitive QA module will be used to analyze relevant information from the knowledge base, and then use machine learning models to generate documents with answer candidates. Then, candidate answers are extracted and ranked, and answer with the highest score will be returned to the user (path (2) in Figure 4).

Open-source components from heterogeneous sources can be utilized in the development of the proposed question-answering system. For example, the Open Ephyra (Seideet al., 2011) framework is an open-source framework representing the state-of-the-art QA system based on IBM's Watson (Ferrucci et al., 2010). The NLP techniques of Open Ephyra are used at Google and in QA systems of other industries (Täckström et al., 2013; Hauswald et al., 2015).

\section{CONCLUSIONS}

AI based cognitive assistants have become increasingly popular as computeraided tools. This study proposes an audit domain cognitive assistant that can be used in the audit brainstorming meeting to help auditors evaluate information and make subsequent judgments.

Computer-assisted audit techniques (CAATs) or computer assisted audit tools and techniques (CAATTs) have been used by auditors as part of their audit procedures 
to improve audit effectiveness and efficiency (Janvrinet al., 2008; Mahzan and Lymer, 2014). Modern CAATs includes basic office software such as spreadsheet (e.g. Excel) and databases (e.g. Access), general data analytics tools (e.g. SAS), and general audit software (GAS) (e.g. ACL and IDEA).

Different from existing CAATs, the proposed audit plan cognitive assistant provides a new method to manage audit knowledge and a new direction of developing CAATs. This paper is the first study that discusses the potential of applying AI based cognitive assistant technology to auditing. The proposed tool could assist auditors in making better judgments in the audit plan risk assessment by retrieving information and providing recommendations. It is a new type of CAATs and auditors can use it with their exiting CAATs. After interacting with this proposed cognitive assistant during the audit plan risk assessment, the engagement team should obtain better understanding of the client and the risk areas, and then they can use other data analytical tools for further data analysis and testing. Thus, the proposed tool will not replace existing CAATs but work as a supplement to them.

Auditor acceptance of CAATs is an important issue to consider during CAATs design and application (Janvrin et al., 2008). Therefore, in the development of the proposed audit cognitive assistant, developers need to carefully consider the actual information needs of audit engagement teams during audit plan, the functions involved in the tool, and the ease of use. One limitation of this study is that the proposed framework needs to be tested through experimental brainstorming meetings. Simulated brainstorming sessions conducted by audit engagement teams will help improve the development of the framework, especially the recommender system and the QA system. The future research on this topic includes: first, the proposed framework and the QA taxonomy should be improved. Second, future research will develop a prototype/demo for the proposed cognitive assistant and test it using experimental brainstorming meetings in the audit plan. 


\section{REFERENCES}

APPELBAUM, D. (2017): "Introduction to Data Analysis for Auditors and Accountants", The CPA Journal, 7.

AICPA (2012): The Risk Assessment Auditing Standards: How to Efficiently and Effectively Comply on Smaller and Less Complex Audit Engagements.

AICPA (2002): Consideration of Fraud in a Financial Statement Audit. https://www.aicpa.org/Research/Standards/AuditAttest/DownloadableDocuments/ AU-00316.pdf

ASARE, S. K.; WRIGHT, A. M. (2004): "The effectiveness of alternative risk assessment and program planning tools in a fraud setting", Contemporary Accounting Research, vol. 21, n. 2: 325-352. https://doi.org/10.1506/1201-7fumfpcb-7be2

BEASLEY, M. S.; JENKINS, J. G. (2003): “A primer for brainstorming fraud risks", Journal of Accountancy, vol. 196, n.6: 32.

BELLEGARDA, J. R. (2013): "Large-scale personal assistant technology deployment: the Siri experience”. In INTERSPEECH, pp. 2029-2033.

BELLOVARY, J. L.; JOHNSTONE, K. M. (2007): "Descriptive evidence from audit practice on SAS No. 99 brainstorming activities", Current Issues in Auditing, vol. 1, n. 1: A1-A11. https://doi.org/10.2308/ciia.2007.1.1.a1

CAMBRIA, E.; WHITE, B. (2014): "Jumping NLP curves: a review of natural language processing research" [review article], IEEE Computational Intelligence Magazine, vol. 9, n. 2: 48-57. https://doi.org/10.1109/mci.2014.2307227

CANBEK, N. G.; MUTLU, M. E. (2016): “On the track of Artificial Intelligence: Learning with intelligent personal assistants", Journal of Human Sciences, vol. 13, n. 1: 592-601. https://doi.org/10.14687/ijhs.v13i1.3549

CARPENTER, T. D. (2007): "Audit team brainstorming, fraud risk identification, and fraud risk assessment: Implications of SAS No. 99", The Accounting Review, vol. 82, n. 5: 1119-1140. https://doi.org/10.2308/accr.2007.82.5.1119

CHEN, G.; PARADA, C.; SAINATH, T. N. (20151): "Query-by-example keyword spotting using long short-term memory networks", In Acoustics, Speech 
and Signal Processing (ICASSP), 2015 IEEE International Conference on (pp. 5236-5240). https://doi.org/10.1109/icassp.2015.7178970

CHUNG, H.; SONG, Y. I.; HAN, K. S.; YOON, D. S.; LEE, J. Y.; RIM, H. C.; KIM, S. H. (2004): “A practical QA system in restricted domains”, In Proceedings of the Workshop Question Answering in Restricted Domains, within ACL.

DAELEMANS, W. (2013): Explanation in computational stylometry. In International Conference on Intelligent Text Processing and Computational Linguistics (pp. 451-462). Springer, Berlin, Heidelberg. https://doi.org/10.1007 1978-3-642-37256-8_37

DAI, J.; LI, Q. (2016): “Designing Audit Apps for Armchair Auditors to Analyze Government Procurement Contracts", Journal of Emerging Technologies in Accounting, vol. 13, n. 2: 71-88. https://doi.org/10.2308/jeta-51598

DOWLING, C.; LEECH, S. (2007): “Audit support systems and decision aids: Current practice and opportunities for future research", International Journal of Accounting Information Systems, vol. 8, n. 2: 92-116. https://doi.org/10.1016/ j.accinf.2007.04.001

DOWLING, C.; LEECH, S. A.; MORONEY, R. (2008): “Audit support system design and the declarative knowledge of long-term users", Journal of Emerging Technologies in Accounting, vol. 5 n. 1: 99-108. https://doi.org/10.2308/ jeta.2008.5.1.99

EBLING, M. R. (2016): “Can cognitive assistants disappear?”, IEEE Pervasive Computing, vol. 15, n. 3: 4-6. https://doi.org/10.1109/mprv.2016.41

FERRUCCI, D.; BROWN, E.; CHU-CARROLL, J.; FAN, J.; GONDEK, D.; KALYANPUR, A. A.; SCHLAEFER, N. (2010): "Building Watson: An overview of the DeepQA project”, AI magazine, vol. 31, n. 3: 59-79. https://doi.org/10.1609/aimag.v31i3.2303

GANDOMI, A.; HAIDER, M. (2015): "Beyond the hype: Big data concepts, methods, and analytics", International Journal of Information Management, vol. 35 n. 2: 137-144.https://doi.org/10.1016/j.ijinfomgt.2014.10.007

GARRIDO, P.; MARTINEZ, F.; GUETL, C. (2010): “Adding semantic web knowledge to intelligent personal assistant agents", In Proceedings of the ISWC 2010 Workshops (pp. 1-12). Philippe Cudre-Mauroux. 
GOFFMAN, N. (2016): The Rise of the Cognitive Assistant. https://www. ibm.com/blogs/insights-on-business/government/rise-cognitive-assistant/

GREENMAN, C. (2017): "Exploring the Impact of Artificial Intelligence on the Accounting Profession", Journal of Research in Business, Economics and Management, vol. 8, n. 3: 1451-1454.

HAMMERSLEY, J. S.; BAMBER, E. M.; CARPENTER, T. D. (2010): “The influence of documentation specificity and priming on auditors' fraud risk assessments and evidence evaluation decisions", The Accounting Review, vol. 85, n. 2: 547-571. https://doi.org/10.2308/accr.2010.85.2.547

HAUSWALD, J.; LAURENZANO, M. A.; ZHANG, Y.; LI, C.; ROVINSKI, A.; KHURANA, A.; MARS, J. (2015): "Sirius: An open end-to-end voice and vision personal assistant and its implications for future warehouse scale computers", In ACM SIGPLAN Notices, vol. 50, n. 4: 223-238. ACM. https://doi.org/10. $1145 / 2775054.2694347$

HIRSCHBERG, J.; MANNING, C. D. (2015): “Advances in natural language processing”, Science, vol. 349, n. 6245: 261-266. https://doi.org/10.1126/ science.aaa8685

HOFFMAN, V. B.; ZIMBELMAN, M. F. (2009): "Do strategic reasoning and brainstorming help auditors change their standard audit procedures in response to fraud risk?", The Accounting Review, vol. 84, n. 3: 811-837. https://doi.org/10. 2308/accr.2009.84.3.811

HUGGINS-DAINES, D.; KUMAR, M.; CHAN, A.; BLACK, A. W.; RAVISHANKAR, M.; RUDNICKY, A. I. (2006): "Pocketsphinx: A free, realtime continuous speech recognition system for hand-held devices", In Acoustics, Speech and Signal Processing, ICASSP Proceedings. IEEE International Conference on, vol. 1:I-I. https://doi.org/10.1109/icassp.2006. 1659988

HUNTON, J. E.; GOLD, A. (2010): “A Field Experiment Comparing the Outcomes of Three Fraud Brainstorming Procedures: Nominal Group, Round Robin, and Open Discussion" (Retracted), The Accounting Review, vol. 85, n. 3: 911-935. https://doi.org/10.2308/accr.2010.85.3.911 
IBM (2017): KPMG Announces Agreement With IBM Watson To Help Deliver Cognitive-Powered Insights. https://www-03.ibm.com/press/uk/en/pressrelease/ 49309.wss

JANVRIN, D.; LOWE, D. J.; BIERSTAKER, J. (2008): Auditor acceptance of computer-assisted audit techniques. Iowa State University, Arizona State University and Villanova University, 4.

KOKINA, J.; DAVENPORT, T. H. (2017): "The Emergence of Artificial Intelligence: How Automation is Changing Auditing”, Journal of Emerging Technologies in Accounting. https://doi.org/10.2308/jeta-51730

LANDIS, M.; JERRIS, S. I.; BRASWELL, M. (2008): "Better brainstorming", Journal of Accountancy, vol. 206, n. 4: 70.

LEVY, S.(2016): An exclusive inside look at how artificial intelligence and machine learning work at Apple. https://backchannel.com/an-exclusive-look-athow-ai-and-machine-learning-work-at-apple-8dbfb131932b

LEE, D. (2016): KPMG Recruits IBM Watson for Cognitive Tech Audits, Insights. https://www.accountingtoday.com/news/kpmg-recruits-ibm-watson-forcognitive-tech-audits-insights

LYNCH, A. L.; MURTHY, U. S.; ENGLE, T. J. (2009): "Fraud brainstorming using computer-mediated communication: The effects of brainstorming technique and facilitation", The Accounting Review, vol. 84, n. 4: 1209-1232. https://doi.org/10.2308/ accr.2009.84.4.1209

MAHZAN, N.; LYMER, A. (2014): "Examining the adoption of computerassisted audit tools and techniques: Cases of generalized audit software use by internal auditors", Managerial Auditing Journal, vol. 29, n. 4: 327-349. https://doi.org/10.1108/maj-05-2013-0877

MEHREZ, T.; ABDELKAWY, A.; HEIKAL, Y.; LANGE, P.; NABIL, H.; SUENDERMANN-OEFT, D. (2013): "Who discovered the electron neutrino? A telephony-based distributed open-source standard-compliant spoken dialog system for question answering”, Proc. of the GSCL, Darmstadt, Germany, 80.

MYERS, K.; BERRY, P.; BLYTHE, J.; CONLEY, K.; GERVASIO, M.; MCGUINNESS, D. L; MORLEY, D.; PFEFFER, A.; POLLACK, M.; TAMBE, 
M. (2007): "An intelligent personal assistant for task and time management", AI Magazine, vol. 28, n. 2: 47.

NIGRINI, M. (2012): "Benford's Law: Applications for forensic accounting, auditing, and fraud detection", John Wiley \& Sons. https://doi.org/10.1002 /9781119203094

POVEY, D.; GHOSHAL, A.; BOULIANNE, G.;BURGET, L.;GLEMBEK, O.;GOEL, N.; HANNEMANN, M.; MOTLICEK, P.; QUIAN, Y.; SCHWARZ, P.; SILOVSKY, J.; STEMMER, G.; VESELY, K. (2011): The Kaldi speech recognition toolkit. In IEEE 2011 workshop on automatic speech recognition and understanding (No. EPFL-CONF-192584). IEEE Signal Processing Society.

RAPHAEL, J. (2017): "Rethinking the Audit: Innovation Is Transforming How Audits Are Conducted-and Even What It Means to Be an Auditor", Journal of Accountancy, vol. 223, n. 4: 28.

RAVURI, S.; STOLCKE, A. (2016): “A comparative study of recurrent neural network models for lexical domain classification", In Acoustics, Speech and Signal Processing (ICASSP), IEEE International Conference on (pp. 6075-6079). IEEE. https://doi.org/10.1109/icassp.2016.7472844

RYBACH, D.; HAHN, S.; LEHNEN, P.; NOLDEN, D.; SUNDERMEYER, M.; TÜSKE, Z.; WIESLER, R.; SCHLÜTER, H.; NEY, H. (2011): Rasr-the rwth aachen university open source speech recognition toolkit. In Proc. IEEE Automatic Speech Recognition and Understanding Workshop.

SEIDE, F.; LI, G.; YU, D. (2011): "Conversational speech transcription using context-dependent deep neural networks", In Twelfth Annual Conference of the International Speech Communication Association.

SEOW, P. S. (2011): "The effects of decision aid structural restrictiveness on decision-making outcomes", International Journal of Accounting Information Systems, vol. 12, n. 1: 40-56. https://doi.org/10.1016/j.accinf.2010.03.002

STRAYER, D. L.; COOPER, J. M.; TURRILL, J.; COLEMAN, J. R.; HOPMAN, R. J. (2017): "The smartphone and the driver's cognitive workload: A comparison of Apple, Google, and Microsoft's intelligent personal assistants", Canadian Journal of Experimental Psychology/Revue canadienne de psychologie expérimentale, vol. 71, n. 2: 93. https://doi.org/10.1037/cep0000104 
TÄCKSTRÖM, O.; DAS, D.; PETROV, S.; MCDONALD, R.; NIVRE, J. (2013): "Token and type constraints for cross-lingual part-of-speech tagging", Transactions of the Association for Computational Linguistics, vol. 1: 112.

TANG, R.; LIN, J. (2017): "Honk: A PyTorch reimplementation of convolutional neural networks for keyword spotting”, arXiv preprint arXiv:1710.06554. 